\title{
Internet research in midwifery:
}

\section{Practical considerations and challenges}

\author{
By Sarah Stewart
}

$\mathbf{T}$ he Internet is being increasingly recognized as a credible source of material for research. Researchers are investigating phenomena such as email discussion groups, bulletin boards and websites (Kralik et al, 2006). The Internet is also proving to be an effective tool for gathering data and recruiting participants (Im and Wonshik, 2004). Nevertheless, it is important to remember that the Internet is a relatively new tool for research, and it is vital that the midwife researcher considers the unique challenges that it generates including intellectual property and copyright, online behaviour in an electronic community, informed consent, anonymity and confidentiality, and dissemination of results. This article will deliberate on these issues and provide practical advice on how to deal with them using international guidelines (Ess and Association of Online Internet Researchers, 2002; National Committee for Research Ethics in the Social Sciences and Humanities (NESH), 2003).

\section{Intellectual property}

There has been considerable debate about intellectual property rights of the written word on the Internet. Intellectual property rights allow authors to control what others do with their work. Does the message on a bulletin board or a birth story published on a web site belong to the writer or is it free for use by anyone in any capacity? Some would argue that birth stories, for example, published on the Internet are fair game for researchers to utilize in their reports without permission or acknowledgement. However, the authors may have published their stories purely as a way to inform other parents. They may object to their writings being used in a research project because that was not the intention of publishing the stories in the first place. All the same, it appears that any material that is freely available on the Internet may be utilized without gaining permission from the author (NESH, 2003). Conversely, material that is not freely available may not be used without permission from the author.

\section{Copyright}

Any material published on the Internet is protected by copyright legislation and should be appropriately acknowledged (Ess, 2004). It is important for the researcher to remember that the Internet is global and may be affected by a number of international copyright laws and conventions. If there is any doubt, the researcher can be guided by the principle of 'fair dealings' (www.copyright.co.nz/zinternet.html). In other words, the researcher may only copy or utilize online material for private study or research. Copying substantial amounts of material, or copying material from web sites into one's own work is not considered 'fair dealings' and thus a breach of

\section{Abstract}

The Internet is an exciting tool for midwifery research; however there are a number of unique challenges that must be addressed. The global and transient nature of the Internet sometimes makes it difficult for the researcher to ensure best practice, but international guidelines provide direction in dealing with these issues. The Internet researcher must ensure anonymity and confidentiality, as well as gain informed consent from research participants. Copyright and intellectual property regulations must be observed, rules of online communities should be respected and an endeavour must be made to ensure that research results are disseminated to all the study participants.

copyright. Having said that, all material should be acknowledged. There may also be times when the researcher wishes to protect the identity of the author in a research report or publication. If revealing the identity of the author is harmful to that person, then it is justifiable to preserve that person's anonymity and publish the material either unacknowledged or with a pseudonym (Ess, 2004).

\section{Online behaviour}

When researching an electronic community such as an email discussion group, the researcher should first consider whether the communication is private or public. There are a multitude of online groups that seek information and social support about any number of sensitive issues. These groups are often 'closed' groups that require registration to join. These groups are usually considered private and populated by especially vulnerable people, which encourages disclosure that would otherwise be unthinkable in a face-to-face encounter (Sharf, 1999). These people might even choose to use pseudonyms, and disguise all identifying features such as their sexual identity and age or create anonymous web-based email addresses to conceal their identity. The researcher cannot make any assumptions about whether community members view their communications as public or private (Frankel and Siang, 1999).

Every online community has its own rules for behaviour so the researcher needs to find out how the community works (Sixsmith and Murray, 2001). Some groups will specifically exclude anyone who is not directly affected or involved with

Sarah Stewart is a PhD candidate at the Centre for Online Health, University of Queensland, Brisbane, Australia Email: sarahs@tekotago.ac.nz 


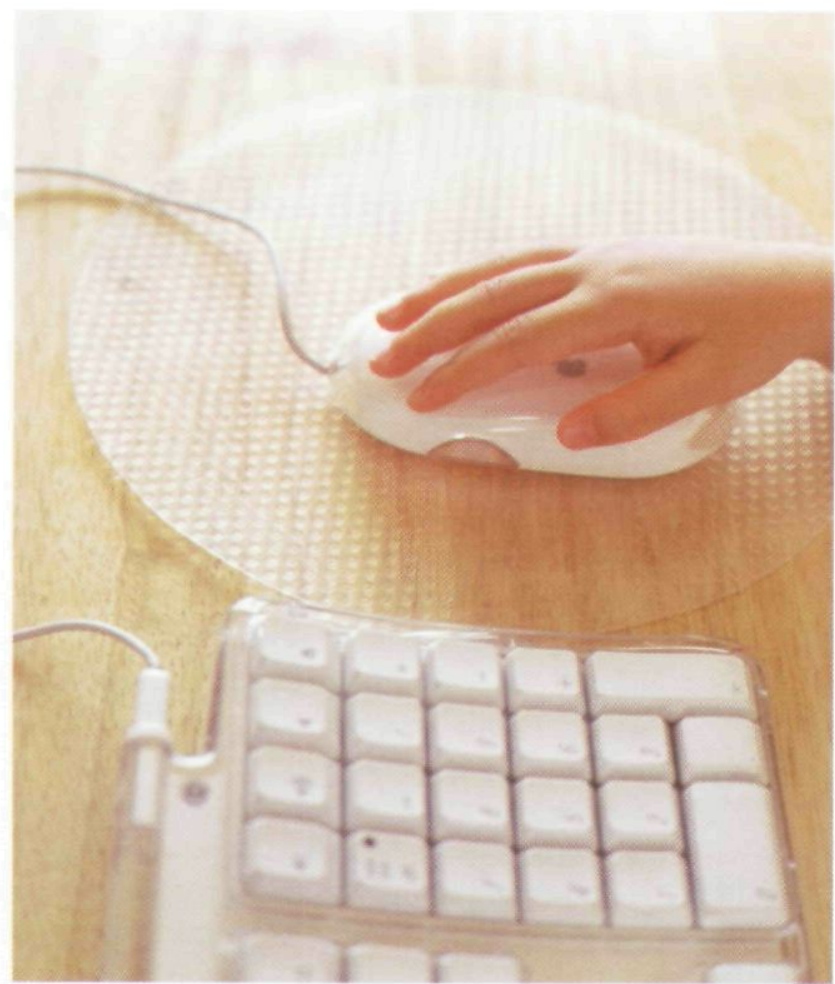

what the group is about. Thus, it is advisable to contact the owner or moderator of the group to make one's presence known and ask for permission to conduct research (Klemm and Nolan, 1998; Ess and Association of Online Internet Researchers, 2002). If the research has the potential to be harmful to the group, especially if it is a vulnerable group or in conflict with the purpose of the group, the researcher must reconsider her research proposal (Sharf, 1999).

The researcher should identify herself and her intention to use the group's words in her research even if she is not going to actively participate in the group (NESH, 2003). By identifying her presence, the researcher may affect how the discussion group operates (Sixsmith and Murray, 2001). In other words, people may be much more guarded about what they say once they know it is going to be quoted. Nevertheless, if the researcher does not inform the group of her presence she could put the participants 'at risk'. Online interactions are very meaningful to participants, and they are likely to feel that their privacy is being violated if they are studied without their knowledge (Hine, 2000).

A further problem a researcher may face is whether to intervene in an email discussion or not. Usually a researcher has an observation role only but one could argue that there is a duty to intervene if the researcher could be of assistance to a group member. The problem with intervening is that the researcher may influence the direction of discussion and interfere with the normal flow of the group. On the other hand, Im and Chee (2001) argue that from the feminist viewpoint researcher and participants should have a reciprocal relationship whereby they interact with each other.

\section{Informed consent}

It is necessary to acquire informed consent from participants taking part in Internet research and inform them of how the material will be used, especially if it is of a personal or sensitive nature (NESH, 2003; Kraut et al, 2004). It is possible to argue that by participating in an email discussion as part of an electronic community, the participant has to accept the risks regarding who is reading their words or what happens to them (Sharf, 1999). For the researcher it can be hugely time consuming to individually email each member of a large electronic community and ask permission to use their words. Another problem is the fluidity of a group; members come and go very quickly. It may be almost impossible to contact members who participated a while ago, although the job becomes a lot easier if there is access to the message archives. Nevertheless, there is increasing agreement between online researchers that if the content of a message is used in a report, each individual author should be asked to give consent and offered complete confidentiality (Ehrenberger and Ehrenberger, 1998).

In the case of web-based surveys, participants imply their consent when they complete and submit a questionnaire (Stewart, 2003). Information about the research may be provided on web pages that participants have to open before they can access the questionnaire. If the researcher is using methods such as online focus groups or synchronous personal interviews, participants will need to be able to read about the research and may complete a consent form (Mann and Stewart, 2000). This can be done in some asynchronous online form such as a web site or bulletin board, or be posted by email. The problem with the online consent form is that the researcher does not know if the participant fully understands the research and its implications (Frankel and Siang, 1999).

In the situation of very sensitive research or where a written signature is required, the researcher can request that the participant downloads the consent form from the Internet, and return it to the researcher by conventional mail. The difficulty with this is that the effort of printing out the consent form and putting it in the letter box may be a disincentive, and could decrease participation rates. When children are research participants, it is advisable to obtain consent from their legal guardians (Mann and Stewart, 2000).

\section{Anonymity}

Participants in Internet research must be confident that their anonymity will be upheld particularly if they have divulged sensitive or personal material. Web-based surveys can provide a degree of anonymity, however, there is the electronic capability for researchers to use 'cookies' which prevents anonymity. Cookies allow a web site to track whoever is accessing it, and can amass information about the user including name, password, pages accessed and type of computer (Jones, 1999). The advantage of cookies is that they will tell the researcher if there are multiple entries from one specific computer. What the cookies cannot tell is if there are multiple users of the computer. One way around the problem is to issue survey participants with unique identifying markers such as individual passwords.

If one is using email as a tool for gathering data, one must bear in mind that it is not a secure system. Email can be intercepted by hackers or by administrators of the email system (Tolich, 2001). One cannot be sure that the email was received by or replied to by the person for whom it was 
intended. emails cannot be completely anonymous because there are always records somewhere of who sent and received the email. To deal with these issues the researcher can use a mixture of electronic and traditional methods, for example invite the participant to mail any sensitive information or consent form by conventional post. The researcher can also use software that operates secure encryption and automatically strips emails of identifying features.

To preserve anonymity, participants of an electronic community often disguise their real identity and take on an online identity, which some researchers would argue reduces risk in quoting messages. However, it is just as important to consider the protection of the online identity as well as the real life identity of the participant (Frankel and Siang, 1999). If the reader of a research report knows the online community that is being discussed, it is quite possible to work out the identity of the person who has been quoted. People pay a lot of attention to their online identities, so it is vital that they are respected in the same way as their real life identities.

\section{Confidentiality}

When it is not possible to maintain complete anonymity, confidentiality must be assured (Table 1). Barnes (2004) recommends that participants be reported as composite personalities instead of reporting participants individually. One must also remember that it is possible to trace the author of material using quotes from a text through search engines such as Google (www.google.co.uk) (NESH, 2003).

\section{Dissemination of research results}

Internet researchers have a responsibility to disseminate the results back to the research participants (NESH, 2003). This can be problematic because of the transient nature of the Internet. The problem of flux particularly applies to electronic communities when members come and go frequently (Im and Chee, 2001). Research results may be disseminated to individual participants, posted to the electronic community or issued to a web site that the participants are informed of when they agreed to enter the research study.

\section{Conclusions}

The Internet lends itself to an assortment of research methods and offers many exciting opportunities for the midwife researcher. Alongside these opportunities come a number of unique challenges that need to be considered and addressed. To increase knowledge in this developing field it is important to disseminate the results of midwifery research including practical advice and technological information so that future researchers are able to utilize the Internet effectively as a tool for research.

BJM

Barnes S (2004) Issues of attribution and identification in online social research. In: Johns M, Chen S, Hall G, eds. Online Social Research: Methods, Issues and Ethics Peter Lang, New York: 203-22

Ehrenberger H, Ehrenberger P (1998) Oncology Nurses Forum 25

(Supplement): 11-15

Ess C (2004) Are we there yet? Emerging ethical guidelines for online research. In: Johns M, Chen S, Hall G, eds. Online Social Research: Methods, Issues and Ethics. Peter Lang, New York: 253-63

Ess C, Association of Online Internet Researchers (2002) Association of
Table 1. Preserving confidentiality of electronic messages

- All headers and signatures should be removed

any reference to the respondent's name or pseudonym should be removed

- Any reference to the name or type of group (e.g. email discussion group or bulletin board) that the participant belongs to should be removed

no reference should be made to the location of the group, for instance the URL (King, 1996)

Online Internet Researchers. Available: http://aoir.org/reports/ethics.pdf (last accessed 24 February 2006)

Frankel M, Siang S (1999) Ethical and legal aspects of human subjects research on the Internet. Available: www.aaas.org/spp/dspp/sfrl/projects/ intres/main.htm (accessed 24 February 2006)

Hine C (2000) Virtual Ethnography. Sage, London

Im E, Chee W (2001) A feminist critique on the use of the Internet in nursing research. ANS Adv Nurs Sci 23(4): 67-82

Im E, Wonshik C (2004) Recruitment of research participants through the Internet CIN:Computers, Informatics, Nursing 22(5): 289-97

Jones, S (1999) Studying the Net; intricacies and issues. In: Jones S, ed.

Doing Internet Research: Critical Issues and Methods for Examining the Net.

Sage, Thousand Oaks: 1-28

King S (1996) Researching Internet communities: proposed ethical

guidelines for the reporting of results. Information Society 12(2): 119-27

Klemm P, Nolan M (1998) Internet cancer support groups: legal and ethical

issues for nurse researchers. Oncol Nurs Forum 25(4): 673-6

Kralik D, Price K, Warren J, Koch T (2006) Issues in data generation using

email group conversations for nursing research. ANS Adv Nurs Sci 53(2):

213-20

Kraut R, Olson J, Banaji M, Bruckman A, Cohen J, Couper M (2004)

Psychological research online: opportunities and challenges. Available: www.

apa.org/science/apainternetresearch.pdf (accessed 24 February 2006)

Mann C, Stewart F (2000) Internet Communication and Qualitative

Research. Sage, London

National Committee for Research Ethics in the Social Sciences and the

Humanities (2003) Research ethics guidelines for internet research.

Available: www.etikkom.no/Engelsk/Publications/internet03 (accessed 24

February 2006)

Sharf B (1999) Beyond Netiquette: the ethics of doing naturalistic discourse

research on the Internet. In: Jones S ed Doing Internet Research: Critical

Issues and Methods for Examining the Net. Sage, Thousand Oaks: 243-56

Sixsmith J, Murray C (2001) Ethical issues in the documentary data

analysis of Internet posts and archives. Qual Health Res 11(3): 423-32

Stewart S (2003) Casting the net: using the Internet for survey research.

British Journal of Midwifery 11(9): 543-46

Tolich M (2001) Self-administered questionnaires: the ethics of snail-

mail vs. email. In: Tolich M, ed. Research Ethics in Aotearoa New Zealand.

Pearson Education NZ, Auckland: 77-86

\section{Key Points}

- The Internet is an exciting tool for midwifery research.

- Internet research must abide by international guidelines ensuring anonymity and confidentiality as well as gaining informed consent from research participants.

- The Internet researcher must observe copyright and intellectual property regulations, respect the rules of online communities and ensure her research results are disseminated to all the study participants. 
Copyright of British Journal of Midwifery is the property of Mark Allen Publishing Ltd and its content may not be copied or emailed to multiple sites or posted to a listserv without the copyright holder's express written permission. However, users may print, download, or email articles for individual use. 